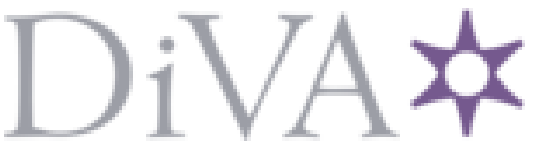

http://www.diva-portal.org

Preprint

This is the submitted version of a paper published in The Journal of product innovation management.

Citation for the original published paper (version of record):

Carnes, C M., Hitt, M A., Sirmon, D G., Chirico, F., Huh, D W. (2022)

Leveraging Resources For Innovation: The Role of Synchronization

The Journal of product innovation management, 39(2): 160-176

https://doi.org/10.1111/jpim.12606

Access to the published version may require subscription.

N.B. When citing this work, cite the original published paper.

Permanent link to this version:

http://urn.kb.se/resolve?urn=urn:nbn:se:hj:diva-54844 


\title{
LEVERAGING RESOURCES FOR INNOVATION: THE ROLE OF SYNCHRONIZATION
}

\section{Journal of Product Innovation Management}

\author{
CHRISTINA MATZ CARNES, Ph.D. \\ MICHAEL A. HITT, Ph.D. \\ DAVID G. SIRMON, Ph.D. \\ FRANCESCO CHIRICO, Ph.D. \\ DONG WOOK HUH, Ph.D.
}

Leveraging resources to develop innovation is central to exploiting market opportunities yet doing so is complex and fraught with challenges. This study explores some of this complexity by theoretically detailing and empirically examining the critical role that synchronization plays in the process of leveraging resources to create innovation. Specifically, we integrate resource orchestration with the behavioral theory of the firm to investigate the joint effect of synchronization and leveraging strategies on innovation under different performance conditions. Using policy capturing methodology resulting in 3,600 observations from 120 managers, we find empirical evidence that synchronization can enhance innovation outcomes of all leveraging strategies. Yet, this positive synergistic effect occurs in high performing firms that use the resource advantage and market opportunity leveraging strategies and in low performing firms that use the entrepreneurial leveraging strategy. Our theory and results offer important contributions to the innovation and resource orchestration literatures. First, our study offers a contextually rich examination of innovation, suggesting that it is not only resources, but also managerial actions and a firm's relative performance that drive innovation outcomes. Specifically, this study adds to our knowledge of the relationship between resources and innovation strategies by investigating the impact of synchronization - a key contingency in understanding the effects of resources on innovation. Second, we examine boundary conditions of synchronization's influence by integrating behavioral logic in the context of relative firm performance. Mixed evidence exists on the synergistic effect of valuable capabilities, with some studies showing increased gains and others finding evidence of a neutral relationship. This study begins to disentangle these findings by suggesting that resource leveraging strategies and synchronization together enhance innovation when the strategy aligns with the firm's relative performance aspirations, answering calls for the development of a more nuanced understanding of the pursuit of innovation.

\section{Practitioner Points}

- Synchronization of internal activities, processes, and subunits involves significant managerial attention, time, and other resources to implement effectively.

- Proper fit between the firm's relative performance and the leveraging strategy chosen is needed to ensure that an investment in synchronization will yield additional, synergistic gains in innovativeness.

- Based on our additional analyses, the inverted U-shaped relationship between synchronization and innovation indicates that internal checks are necessary to ensure synchronization is not taken to an extreme such that inefficiencies and costs outweigh the potential positive direct and synergistic benefits of synchronization

\section{Keywords}

Synchronization, Innovation, Resource Orchestration, Performance aspirations

\section{Acknowledgements:}

The author team would like to thank Yasemin Kor, Tony Tong, Justin Webb, and Ralf Wilden for their comments on an earlier version of this paper. We are also particularly grateful to the anonymous review team and Editor Jelena Spanjol for their helpful comments and guidance throughout the review process. 


\section{INTRODUCTION}

With the rapid pace of technological change, shortened product life cycles, and the increase in global competition, innovation is a critical basis of competitive advantage, and key to long-term survival for many firms (Danneels, 2002, Troilo, De Luca and Atuahene-Gima, 2014). An important stream of research exploring innovation drivers has originated from resource-based logic, suggesting that valuable, rare, inimitable, and non-substitutable resources are critical for innovation (Branzei and Vertinsky, 2006, Coates and McDermott, 2002, De Massis et al., 2018). As such, previous research has identified the importance of firm resources and capabilities for both the innovation process (Randhawa, Wilden and Gudergan, 2018) and innovation-relevant outcomes (Pollok, Lüttgens and Piller, 2019). Yet, while the control of superior resources and capabilities is important, it is insufficient to develop innovation. To do so requires that firms "efficiently orchestrate their resources to innovate and outcompete their competitors in the global market" (De Massis, et al., 2018: 136); more specifically, resources and capabilities need to be managed and leveraged in a way that supports innovation (Lichtenstein and Brush, 2001). As Miller, Eisenstat, and Foote (2002: 47) argue, even the "most integrated configurations (of capabilities) are of no value unless they extract superior returns." Thus, the quality of managerial resource allocations and decisions related to new product development is critical for organizational performance (Antioco, Moenaert and Lindgreen, 2008).

The strategies used by firms to leverage their resources and capabilities represent their strategic choice about how to engage a market (Sirmon and Hitt, 2003) by extracting value from the firm's resources and capabilities (Sirmon, Hitt and Ireland, 2007). To effectively implement any leveraging strategy (Sirmon et al., 2007), the firm must support it with complementary internal actions; otherwise, the firm may not experience the innovation gains expected (De 
Massis, et al., 2018, Hrebiniak, 2005, Repenning, 2002). These internal actions are the purview of managers. Nonetheless, much of the prior work in innovation at the firm level has focused on the combination of various resources needed to develop higher levels of innovation (Kleinschmidt, De Brentani and Salomo, 2007, Song, Song and Anthony Di Benedetto, 2011), and has largely ignored the specific role of managers, who are responsible for actually orchestrating these resources under various constraints (Baert et al., 2016). Defined as the integration and coordination of actions to manage the resources within the firm to support and implement a leveraging strategy, synchronization reflects managerial efforts to align internal processes, including acquiring and developing resources, building capabilities, and ultimately designing and implementing a strategy to leverage those capabilities (Sirmon, et al., 2007, Sirmon et al., 2011). While prior literature has emphasized synchronization's importance, it has failed to underscore that the effects of synchronization are context dependent (Lin et al., 2017).

To address this oversight, the present study integrates insights from the literature on resource orchestration (RO) with the behavioral theory of the firm (BTOF). We focus on how synchronization, and leveraging strategies jointly affect innovation outcomes (Sirmon, et al., 2007) and how this relationship is dependent on a firm's performance relative to its rivals (Cyert and March, 1963). That is, while we theorize that synchronization can enhance innovation outcomes, we expect the benefits to vary based on the firm's choice of leveraging strategy, and the strategy's fit with the firm's performance relative to peers. With supportive empirical results based on 3,600 observations from 120 managers, several important contributions arise from this study.

First, our study offers a contextually rich approach for understanding the relationship between leveraging strategies, synchronization, and innovation, showing that it is not resources 
alone, but also managerial actions and a firm's relative performance that influence innovation outcomes. While RO has traditionally focused on understanding firm performance (Sirmon, et al., 2011); by extending this theory's application to firm innovation in this study, we address previous calls for new theoretical insights into innovation success factors (Evanschitzky et al., 2012, Lin, et al., 2017). Second, we examine boundary conditions of synchronization's influence by integrating behavioral logic in the context of relative firm performance. Mixed evidence exists on the synergistic effect of valuable capabilities, with some finding increased gains (Sirmon and Hitt, 2009) and others finding evidence of a neutral relationship (Huesch, 2013). This study begins to disentangle these mixed findings by suggesting that leveraging strategies and synchronization produce synergistic benefits for innovation when the strategy aligns with the firm's relative performance aspirations. In this way, the study answers calls for the development of a more nuanced understanding of the contingencies surrounding the pursuit of innovation (Ahuja, Lampert and Tandon, 2008). In addition to the theoretical advances provided by this study, our work enhances our understanding of how business executives and managers can best promote innovation through strategic resource orchestration (Antioco, et al., 2008, De Massis, et al., 2018, Lin, et al., 2017).

\section{THEORETICAL BACKGROUND}

\subsection{Innovation}

Innovation, defined as "the commercial application or adoption of an invention [i.e., a new idea]" (Fleming, 2001: 117-118, Makri, Hitt and Lane, 2010), is a strategic outcome that contributes to the renewal and success of organizations (Branzei and Vertinsky, 2006, Danneels, 2002, Subramaniam and Venkatraman, 2001). Prior research has established three concepts key to innovation: risk, slack, and resource recombination. 
Innovation involves risk, and risk-taking actions including innovation (e.g., Chen, 2008, Chen and Miller, 2007, Gaba and Bhattacharya, 2012, Greve, 2003) have been extensively studied based on the BTOF (Cyert and March, 1963). One aspect of BTOF is that organizational goals, or aspirations, are set in the context of the firm's perceived performance relative to its rivals in the market. The BTOF predicts that organizations appear to be risk-seeking below the target [i.e., aspiration level], [and] risk-averse above it" (Cyert and March, 1992: 228), and indeed, research has found that relative firm performance is highly salient in managers' risktaking decisions (Hoskisson et al., 2017).

A core concept for innovation and the BTOF is slack, or excess resources. With few exceptions (e.g. Gibbert, Hoegl and Valikangas, 2014, Latham and Braun, 2009), most research shows that slack facilitates risk taking in general (Arrfelt, Wiseman and Hult, 2013, Barreto, 2012) and innovation in particular (Chen, 2008, Chen and Miller, 2007, Greve, 2003, O'Brien and David, 2014, Vissa, Greve and Chen, 2010). Slack supports innovation in a variety of ways, including by providing firms with greater freedom in project selection and exploration, allowing them to engage in riskier choices and by causing firms to innovate internally to meet market demands (George, 2005, Troilo, et al., 2014).

Scholars have proposed that the ultimate source of novelty in successful innovation lies in the recombination of conceptual and physical resources (Nelson and Winter, 1982). As such, the realization of an innovative project requires effective management of available resources to produce these innovative new combinations (Paladino, 2007, Sirmon, et al., 2007). According to the resource-based view, a central task of managers is the optimal allocation of scarce and valuable resources (Barney, 1991, Wernerfelt, 1984). Thus, to explore how managers can 
promote successful innovation outcomes, we turn to resource orchestration theory, a body of literature that focuses on managerial action and decision-making.

\subsection{Resource Orchestration}

\subsubsection{The role of managers}

RO research concerns managerial strategy, decisions, and actions. RO identifies managerial roles in three broad categories: (1) structuring, (2) bundling, and (3) leveraging. Structuring captures the subprocesses associated with acquiring, accumulating, and divesting the resources; bundling encompasses the subprocesses associated with combining, integrating, and transforming resources into capabilities; and leveraging involves the deployment of the capabilities to create value (Helfat and Peteraf, 2003, Sirmon, et al., 2007).

\subsubsection{Leveraging strategies}

Of the three managerial roles, leveraging is arguably the most crucial. Leveraging strategies are externally oriented, and determine how the firm engages with the market using its resources and capabilities to create value (Sirmon and Hitt, 2003, Sirmon, et al., 2007). RO research has identified three types of leveraging strategies: the resource advantage strategy, the market opportunity strategy, and the entrepreneurial strategy (Sirmon, et al., 2007, Sirmon, et al., 2011).

The resource advantage strategy is designed to leverage the current internal capabilities of the firm to strengthen its position in a market in which it already has an advantage. For example, when Anheuser-Busch InBev acquired SABMiller in 2015, it used its existing capabilities in marketing and distribution to expand its advantage over competitors in the beer market. Innovations using this leveraging strategy are most likely to produce improvements in existing products and expand existing markets. The market opportunity strategy involves 
reconfiguring existing capabilities to exploit opportunities identified in the external environment. Some examples of this strategy are expanding the geographic market of a successful product, or using marketing, R\&D, and/or engineering capabilities to make changes to an existing product that satisfy new or developing consumer needs. For instance, Steve Jobs' well-known pivot from using touch-screen technology for the iPhone to the iPad reconfigured an existing capability to target a new market opportunity he identified. This strategy is likely to produce innovations that enrich current products or support existing products entering a new market. The entrepreneurial strategy requires developing novel capability configurations to create new products or services, and/or develop new markets, in essence creating new (entrepreneurial) opportunities for the firm. Examples include the creation and proliferation of telemedicine by firms such as CareClix, virtual reality headsets by such firms as Oculus Rift, and even commercial space flight by firms such as SpaceX. This strategy leads to the most novel forms of innovation.

In summary, the resource advantage strategy leverages current capabilities in a current market, the market opportunity strategy leverages current capabilities in a new market, and the entrepreneurial strategy leverages new capabilities in a new market.

\subsubsection{Synchronization}

Synchronization refers to the managerial process of integrating and coordinating RO actions within the firm to support and implement a specific leveraging strategy (Sirmon, et al., 2007, Sirmon, et al., 2011). Synchronization is complicated as it involves significant managerial attention, time, and other resources to implement effectively. In other words, synchronization requires effective integration and coordination across management levels and units within an organization, so that they work together like a well-oiled machine (Greer, Lusch and Hitt, 2017, Hitt et al., 2017). For example, if a firm decides to adopt a new 'direct to consumer' distribution 
model as part of a market opportunity strategy, its managers will have to coordinate changes to internal processes across the organization, which potentially involves changes in human capital, information technology, and/or financial resources, among others to ensure they all support the firm's overall strategy. ${ }^{\mathrm{i}}$

Prior work in RO suggests that even though each RO process can create value, superior gains are realized when all of the internal processes are synchronized (Sirmon, et al., 2011) allowing firms to hopefully achieve an "optimal” resource allocation (Gibbert, et al., 2014). Sirmon and Hitt (2009) found that synchronization of structuring and bundling subprocesses (e.g., they have the appropriate resources available to create the capabilities needed to support the strategy for the market) leads to positive outcomes, and a lack of synchronization across these two processes leads to negative outcomes - regardless of which actions are used.

Despite its theoretical importance in the resource orchestration literature, however, there remains a dearth of empirical studies on synchronization. Thus, the mechanisms connecting synchronization to positive innovation outcomes are not well understood (Troilo, et al., 2014). In

this study, we examine the relationship between the specific leveraging strategy used, degree of synchronization achieved in the firm (RO), the firm's relative performance (an indicator of risk propensity) (BTOF), and innovation outcomes, from the point of view of the managers responsible for managing the resources.

\section{HYPOTHESIS DEVELOPMENT}

Prominently we argue that synchronization helps to generate slack resources, which can be used in the development of innovation. We suggest two mechanisms by which synchronization can produce slack that in turn can enhance the innovative outcomes for any leveraging strategy. First, multiple studies indicate that innovation requires cascading sets of 
integrated actions across different parts of the firm (Bonaccorsi and Lipparini, 1994, Emden, Calantone and Droge, 2006, Hitt et al., 1999, Joglekar and Rosenthal, 2003). For example, if an entrepreneurial leveraging strategy is pursued to develop new products, new capabilities require new bundling processes, thereby requiring new resources (Kusunoki, 1997, Sirmon, et al., 2007). Such complex interactions across the firm produce multiple opportunities for friction. By coordinating changes and integrating activities across multiple areas of the firm, synchronization can reduce friction and increase efficiency to translate the levering strategy in higher innovation outcomes.

Second, prior research has identified a bias towards equal allocation of resources across the units of an organization, regardless of actual need or performance (Bardolet, Fox and Lovallo, 2011). This bias potentially leaves certain intrafirm groups with unidentified slack, while other groups may lack the resources needed to fully support the implementation of a firm's leveraging strategy. With greater synchronization, managers can coordinate resources across processes and between units allocating resources to meet each unit's specific needs, thereby enabling greater utilization of resources across the firm (Bonaccorsi and Lipparini, 1994, Emden, et al., 2006). In other words, synchronization can reduce these imbalances and optimize utilization of resources across the firm.

Thus, by reducing friction and identifying misallocated resources, the managerial process of synchronization can potentially make slack resources available for use in a leveraging strategy, boosting innovation outcomes. We predict that synchronization positively moderates the relationship between each leveraging strategy and innovation. In formal terms:

Hypothesis 1a: Synchronization strengthens the positive relationship between innovation and each of the three leveraging strategies: (a) resource advantage strategy, (b) market opportunity strategy, and (c) entrepreneurial strategy. 


\subsection{Differential Impact of Performance}

Next, we suggest that the relationship among synchronization, leveraging strategy, and innovation is also influenced by the firm's relative performance context, which plays an important role in the choice of leveraging strategy.

Prior research indicates that high-performing firms, as opposed to low-performing firms, often have strong internal capabilities and available slack to seek out and exploit external opportunities in existing markets (Voss, Sirdeshmukh and Voss, 2008). Firms performing above their aspirations generally engage in behaviors that safeguard their current performance. While continuing to pursue innovation, high performing firms often (1) bound the risk in the strategies they pursue with the intent to maintain current advantages and the favorable status quo (Chandy and Tellis, 2000, Harris and Bromiley, 2007, Morrow et al., 2007), and (2) try to avoid losses by investing in projects that largely build on or incrementally improve current capabilities rather than trying to develop new and unique capabilities (De Massis, et al., 2018). Given this, the resource advantage and market opportunity strategies are a good fit for high performing firms.

In these cases, synchronization enables greater coordination and resource sharing across activities and markets, allowing the high performing firm to take advantage of their knowledge and effectively 'do more with less'. In other words, we argue that synchronization helps high performing firms use their slack resources efficiently and effectively in conjunction with their current capabilities, similarly to the mechanisms proposed in Hypothesis 1. Thus, for firms with high performance relative to rivals, synchronization provides the greatest positive synergy when the firm chooses leveraging strategies that build on their current capabilities and allow them to expand their current products into new markets (i.e., the resource advantage and market opportunity leveraging strategies). In other words, we argue that high performing firms may 
increase their leveraging strategy's innovativeness with synchronization, but these benefits are maximized when they use a resource advantage strategy or market opportunity strategy. Formally:

Hypothesis 2a: The positive moderation effect of synchronization on the resource advantage strategy-innovation relationship exists in high-performing firms as opposed to low-performing firms.

Hypothesis 2b: The positive moderation effect of synchronization on the market opportunity strategy-innovation relationship exists in high-performing firms as opposed to low-performing firms.

Firms that are performing below their aspirations exhibit markedly different behavior from high performing firms (Massini, Lewin and Greve, 2005). Specifically, poor performance (1) stimulates increased risk taking (Harris and Bromiley, 2007, Kotlar et al., 2014, Mishina et al., 2010), (2) serves as a catalyst to identify new practices (Alexy, Bascavusoglu-Moreau and Salter, 2016, Kotlar, et al., 2014), and (3) motivates the replacement of existing, poorly performing capabilities with new capabilities that enhance innovation (Cyert and March, 1963, Singh, 1986). In other words, because they are less attached to their current market position, low performing firms search broadly for new opportunities, and, after one is identified, they must realign their internal actions to fit the new opportunity. These behaviors are consistent with an entrepreneurial leveraging strategy. The entrepreneurial strategy does not build on current capabilities; instead it seeks to replace current activities through a process of Schumpeterian creative destruction (Sirmon, et al., 2007).

In these cases, the low-performing firm often needs to develop slack resources that will allow them to build new capabilities and pursue new advantages, and synchronization helps them build that slack. Prior research has found that firms with less slack exhibit specific resource management behaviors (Gibbert, et al., 2014), often forcing managers to improve allocative 
efficiency (Baker and Nelson, 2005, George, 2005, Starr and MacMillan, 1990, Troilo, et al., 2014). In this context, by increasing efficiencies and reducing friction, synchronization enables a poorly performing firm to build the slack resources it needs, which can then be deployed to build new capabilities as part of an entrepreneurial leveraging strategy. Accordingly, we predict

Hypothesis 2c: The positive moderation effect of synchronization on the entrepreneurial strategy-innovation relationship exists in low-performing firms, as opposed to highperforming firms.

In summary, slack is a key mechanism for how synchronization creates benefits for both high- and low-performing firms; however, synchronization supports slack in different ways depending on the context. High performing firms often have slack and tend to restrict their innovation investments to capitalize on current advantages. Synchronization helps these firms use existing slack resources efficiently and effectively in conjunction with their current capabilities. Low performing firms do not have current advantages on which to capitalize, so synchronization helps them to build slack in their organizations to support changing their resources and capabilities.

\section{METHODS}

To investigate our hypotheses, this study employs the policy capturing method. Policy capturing is a method designed to capture the judgments of decision makers (Hitt and Middlemist, 1979, Stumpf and London, 1981), and is specifically useful for examining decisions in which levels of critical components vary across situations (Connelly, Miller and Devers, 2012). By detecting differences in managers' reactions to decision criteria, policy capturing helps to identify heuristics used in these decisions. Further, by combining demographic information about the manager and the firm with data from policy capturing, researchers can explore contextual influences on managers' decisions. 
Considered as a field-experiment technique (Bollinger et al., 2021, Reuer et al., 2013), policy capturing provides effective insights into decision-making (Connelly, et al., 2012, Reuer, et al., 2013), and has been used by management researchers in a variety of studies because of its ability to reduce self-report biases, ensure reliability of measures, and control for external sources of variance and alternative explanations (Connelly, et al., 2012, Devers, Wiseman and Holmes, 2007). Previous studies have found that it accurately reflects actual managerial decision-making as evaluated by executives to whom the managers report (Hitt et al., 2000, Hitt and Middlemist, 1979).

Though originally developed in social judgment theory, policy capturing has experienced a resurgence in recent research across a variety of contexts and questions. Hitt and colleagues used policy capturing in a series of studies (Hitt et al., 2004a, Hitt, et al., 2000) to investigate alliance partner selection across various countries and institutional contexts, such as emerging, transitional, and developed economies. Devers, Wiseman, and Holmes (2007) used policy capturing to understand the relative value of various types of stock option compensation. Connelly, et al. (2012) used the policy capturing method to study trust and distrust in interorganizational contracting. Recently, Reuer, et al. (2013) used this same method to study governance choices in international joint ventures (IJVs); a follow-up study by Tong et al. (2015) examined factors that affect assessments of IJVs as modes for engaging in inward foreign direct investment. In our study, the policy capturing method allows us to identify the influence of a number of variables on a single outcome, innovation.

\subsection{Instrument Design}

Policy capturing is a repeated measures experimental design. Instead of randomly assigning participants to different conditions, as in a survey approach, in this method we ask all 
participants to respond to a variety of scenarios (i.e., conditions) representing different combinations of variables, and observe the variance in their responses, yielding insights about the interrelationships among the variables. ${ }^{\text {ii }}$ For this study, our independent variables consisted of seven resource management processes and three leveraging strategies, all derived from the existing theory and research on resource orchestration (Sirmon, et al., 2007, Sirmon, et al., 2011). The level of each variable in a scenario was described by a Likert-style five-point scale (low, moderately low, average, moderately high, and high).

The first part of the main body of the instrument was designed to collect demographic information regarding the responding executive and his or her firm. The second part, which constituted the bulk of the instrument, presented 30 scenarios describing hypothetical companies with different levels of each variable, and asked the respondent to rate each hypothetical company in terms of its propensity to innovate. To aid study participants, we included detailed instructions on how to complete the instrument and a set of definitions of the key terms used in the instrument. Then, we were able to compare responses among respondents and investigate relationships among different variables. Because of the nested nature of these data, with multiple scenarios for each respondent, hierarchical linear modelling (HLM) was used to control for the between- and within-respondent differences in the data.

To reduce multicollinearity between our given criteria values across scenarios, we assigned the levels of the items randomly. At the same time, we ensured that the variance of the levels of each item was balanced so that each item had approximately the same probability of influencing a respondent's evaluations of the scenarios. We generated random levels of the items multiple times to identify an acceptable combination of both conditions. This design approach allowed us to isolate the $\mathrm{RO}$ processes that were driving the decisions for each respondent. 
After the initial version of the instrument was created, we conducted a pilot test with 13 managers from firms similar to but not included in the final sample, to assess the efficacy and clarity of the instrument. The pilot study helped us to test the managers' understanding of the instrument and determine if they experienced any difficulties. The pilot study participants all completed the instrument within 25-30 minutes; their feedback suggested that the time required was reasonable. We confirmed the pilot participants' understanding of each of the terms used and the style in which the information was presented in each scenario and made minor changes based on their feedback to ensure clarity in the final version of the instrument.

Finally, we conducted eight follow-up validation interviews with managers that were similar to, but not included, among the managers in our final sample. In these interviews, we sought to assess the validity of our instrument, asking questions regarding their thought process when assessing innovation potential, both in their own firms and in hypothetical situations. The responses unanimously supported our approach. For example, when asked if a manager could judge a firm's level of innovativeness given a list of the firm's resources and their levels, all respondents said yes. As one respondent commented, "Entrepreneurs learn to think quickly and elaborate information quickly - this is what we need to do! So, looking at a number of resources available and levels, I can assess the potential innovation outcome. I do [this] all the time as an internal analysis of my company." Given the consistency of these responses, along with prior research establishing the validity of the instrument design used (Hitt and Middlemist, 1979), we conclude that this instrument provides an accurate means to examine the decision making process for managers, especially their assessment of the relationships between resource orchestration processes and innovation. 


\subsection{Sample}

To invite study participants, we used a random subsample of 600 entrepreneurial firms that had been identified by the entrepreneurship center of a large research university located in the southwestern United States. Of these identified firms, 256 firms had current contact information. We invited top executives of these firms to participate in our study by direct phone calls. Upon obtaining an executive's consent to participate, we sent the executive an online link to our instrument. We received complete data from 120 firms, yielding a participation rate of 46.9\%. The final median completion time for our respondents was 29 minutes, with a mode of 20 minutes, both in line with our pilot study.

Our final sample consisted of 120 questionnaires with 30 scenarios each, resulting in 3,600 observations. The median age of firms in our sample is 15 years, with a range from less than 1 year to 125 years, while the median firm size is 30 employees with a range from 1 to 300,000 employees. Approximately $85 \%$ of firms are private, and 31\% are family businesses. All major industry sectors are represented; however, firms in the service industries comprise nearly $60 \%$ of our sample. The average manager who completed the instrument has a firm tenure of nearly 11 years and industry tenure of slightly more than 20 years. CEOs compose $50 \%$ of the responding managers, with the remaining respondents being high-level managers an average of two levels below the CEO.

\subsection{Dependent Variable}

Innovation was a two-item scale. Respondents were instructed to evaluate each scenario and rate the extent to which the configuration of sub-processes and strategies described would be conducive to achieving innovation. Specifically, they were asked the following two questions:

(1) if tasked with facilitating innovation, how likely would they be to recommend the given 
resource management configuration to their firm, and (2) how likely would the given configuration be to contribute to the firm's level of innovation. Thus, the dependent variable innovation represents the propensity of a given hypothetical firm to develop innovation in the presence of a specific configuration of RO processes and strategies, as evaluated by a manager. In other words, this dependent variable captures managers' judgments about the innovative ability of firms given certain firm attributes.

Respondents were asked to provide a response to each question on a five-point scale. The coefficient alpha for this measure was 0.91 and the inter-item correlation was 0.85 , which suggest a high level of internal reliability.

\subsection{Independent Variables}

The scenarios presented our four independent variables: synchronization, resource advantage strategy, market opportunity strategy, and entrepreneurial strategy. Synchronization represents the integration of resource orchestration activities for a desired firm outcome. Presented as a single criterion in all scenarios, synchronization was explained to participants as accurately depicting the hypothetical firm's level of integration and coordination to ensure efficiency across the resource orchestration activities. As with all criteria in the scenarios, the level of synchronization was experimentally manipulated across the 30 scenarios on a Likerttype 5-point scale. Thus, a high synchronization value suggests a strong alignment between resource orchestration activities, while a low value suggests that the firm's resource orchestration activities are disconnected.

Each of the three leveraging strategies were similarly presented on a Likert-type 5-point scale and manipulated across the 30 scenarios. The resource advantage strategy represents a firm's engagement in leveraging internal capability configurations in current markets. A high 
value represents a major use of this approach while a low value suggests minimal engagement in this strategy. The market opportunity strategy represents a firm's engagement in exploiting external market opportunities to extend current capabilities. The entrepreneurial strategy represents a firm's engagement in developing entirely new capabilities for a completely new market.

The final independent variable, performance, was derived from the contextual data captured in the first part of the instrument. Rather than varying across scenarios, the relative performance variable was a respondent characteristic, calculated as a composite of four items from the demographic portion of the questionnaire: the executive's ratings of net profit, growth in net worth, sales growth, and cash flow relative to rivals over the last 3 years on a 5-point scale with 1 being 'much worse than competitors' and 5 being 'much better than competitors'

(Wiklund and Shepherd, 2003). This scale had a high internal reliability with a coefficient alpha of 0.86. Deriving this variable from the respondent's own self-rated perceptions provided a more direct route to capturing the actual context of managerial decision making than using objective measures of financial performance. To create disparate groups of firm performance for analysis, the firms were then cluster analysed based on this composite measure. Using k-means clustering with Euclidean distance, we obtained a two-cluster solution, which produced a high-performance group and a low performance group. ${ }^{\text {iii }}$

\subsection{Control Variables}

We incorporated a number of controls in our analyses. Within the scenarios, we controlled for the levels of 6 structuring and bundling sub-processes (acquiring, accumulating, divesting, stabilizing, enriching, and pioneering), each manipulated across scenarios on a five- 
point scale. These controls ensured that the variance explained by synchronization and leveraging strategies was beyond that explained by other RO actions.

Second, we included several firm-level variables as controls derived from the demographic part of the instrument: firm size, family business, R\&D intensity, and life cycle stage. Firm size may influence the availability of slack resources (Zahra and Nielsen, 2002) or the existence of market power. Firm size was captured as the log of the total number of employees in the firm. A family business dummy $(1=$ family $)$ was included because family firms may be more risk-averse or less likely to engage in innovation to avoid risking loss of their socioemotional wealth (Gómez-Mejía et al., 2007). $R \& D$ intensity was controlled, as the level of R\&D in a firm can be a determinant of innovation (Cohen and Levinthal, 1990). This variable was represented by the percentage of key employee time or other valuable firm resources invested in developing new ideas, products, or services, as reported by the respondent in part one of the questionnaire. Finally, life cycle stage (start-up, growth, maturity, revitalization, and decline), operationalized as a categorical variable, ${ }^{\text {iv }}$ was included as a control because it may influence a firm's approach to innovation (Agarwal, Sarkar and Echambadi, 2002, Sirmon, et al., 2011).

Third, we controlled for industry influences, because prior research suggests that different industries have dissimilar levels of innovation (Makri, et al., 2010). Respondents reported the industry to which their firm belonged, and we grouped these into 5 broad categories based on the NAICS codes: (1) Mineral and Construction, (2) Manufacturing, (3) Financial, Services, and Communication, (4) Wholesale, Retail, and Distribution, and (5) Government, Public Administration, and Other. Industry was operationalized as a categorical variable. The 
Wholesale, Retail, and Distribution had the smallest representation in our sample and thus was omitted from the models and used as the reference category.

\section{RESULTS}

HLM was used to analyze the data for testing our hypotheses, as it is particularly appropriate for policy capturing methods (Hitt, et al., 2004a, Hitt, et al., 2000). Our study design creates two levels in the data, scenarios nested within respondents, so each respondent's evaluation of the scenarios cannot be considered independent. HLM controls for potential autocorrelation and heteroscedasticity by accounting for within-respondent variance as well as between-respondent variance (Hofmann, 1997). The coefficients produced by HLM can be interpreted similarly to those of OLS regression; in fact, because the independent variables had relatively equal variance due to our study design, the resulting coefficients largely proxy standardized coefficients in which the relative weights can be interpreted (Hitt, Boyd and Li, 2004b, Hitt, et al., 2000). The 120 responses generated 3,600 total observations, which provide strong statistical power, thereby alleviating Type II error concerns. The descriptive statistics and correlation matrix for all variables are presented in Tables 1 and 2.

Insert Tables 1 and 2 about here

Models 1 and 2 presented in Table 3 incorporate the control variables and direct effects. Model 3 introduces the two-way interactions while Models 4 and 5 present the performance subgroup analyses. All independent variables were centered before they were added to our models.

Insert Table 3 about here 
The theoretical logic developed for the hypotheses suggests two moderators for the leveraging strategy-innovation relationship. First, synchronization enhances the relationship between each leveraging strategy and its innovation outcome. Second, the firm's relative level of performance moderates the synchronization-leveraging strategy-innovation relationship such that for high performing firms the relationship only exists for the resource advantage and market opportunity strategies, and low performing firms only exhibit the relationship for the entrepreneurial strategy.

These two moderators represent the two different types of moderation: strength and form. As explained by Hitt, et al. (2004b: 7) "[m]oderation can be further decomposed into two varieties: strength and form. Strength moderation occurs when the intensity of the relationship between $\mathrm{x}$ and $\mathrm{y}$ is different at varying levels of $\mathrm{z}$, and is analyzed via subgroup analysis (Arnold, 1982). Alternatively, form moderation occurs when the form of the $\mathrm{x}-\mathrm{y}$ relationship is determined by levels of $\mathrm{z}$ and is analyzed via an interaction term. Strength and form analyses test different types of relationships, and hence should not be considered substitutes for each other" (italics in original) (see also Arnold, 1982, Venkatraman, 1989). Accordingly, we use strength and form moderation tests separately for our analyses depending on the type of relationship hypothesized. To test our synchronization moderation predictions, we employ interaction terms, as these hypotheses suggest changes in the form of the relationship. Alternatively, we employ subgroup analysis to test our high and low performance predictions, as these hypotheses suggest changes in the strength of the relationship.

Hypotheses 1a, 1b, and 1c proposed that synchronization has a positive moderating effect on the relationship between innovation and, respectively, the resource advantage, market opportunity, and entrepreneurial strategies. The results for these hypotheses are presented in 
Model 3 of Table 3 . The coefficient of the interaction term between resource advantage strategy and synchronization is positive and statistically significant $(\mathrm{p}<0.05)$. Thus, Hypothesis $1 \mathrm{a}$ receives support. The interaction coefficient between the market opportunity strategy and synchronization is also positive and statistically significant $(\mathrm{p}<0.05)$, providing support for Hypothesis $1 b$. Lastly, the interaction coefficient for entrepreneurial strategy and synchronization on innovation is marginally statistically significant $(\mathrm{p}<0.10)$. Therefore, Hypothesis $1 \mathrm{c}$ receives moderate support.

Hypothesis 2a posits that the moderating effect of synchronization on the resource advantage strategy-innovation relationship is present in high performing firms as opposed to low performing firms. The coefficient for the interaction of the resource advantage strategy and synchronization in the high-performance subgroup shown in Model 4 is positive and statistically significant $(\mathrm{p}<0.05)$. Simultaneously, the coefficient for the interaction of the resource advantage strategy and synchronization in the low performance subgroup shown in Model 5 is not statistically different from zero. Comparing the coefficients across models reveals a statistically significant difference between the high and low performance subgroup interaction coefficients. These results provide support for Hypothesis 2a.

Hypothesis $2 b$ similarly suggests that the moderating effect of synchronization on the market opportunity strategy-innovation relationship is present in high-performing firms as opposed to low performing firms. The coefficient for the interaction of the market opportunity strategy and synchronization in the high-performance subgroup (Model 4) is positive and statistically significant $(\mathrm{p}<0.01)$. Also, the coefficient for the interaction of the market opportunity strategy and synchronization interaction in the low performance subgroup shown in 
Model 5 is not statistically different from zero. Additionally, these interaction coefficients are statistically different across the models. These results provide support for Hypothesis $2 b$.

Hypothesis $2 \mathrm{c}$ proposes that the moderating effect of synchronization on the entrepreneurial strategy-innovation relationship is present in low performing firms as opposed to high performing firms. As shown in the low performance subgroup (Model 5), the interaction term between synchronization and the entrepreneurial strategy is positive and statistically significant $(\mathrm{p}<0.05)$, while this same coefficient is not statistically significant in the highperformance subgroup (Model 4). Again, comparing the interaction coefficients across models, the difference is statistically significant. These results provide support for Hypothesis 2c.

Overall, these findings show support for our arguments that the effect of synchronization is context-dependent such that this synergistic relationship is only present when the leveraging strategy aligns with the firm's relative performance aspiration.

\subsection{Post-Hoc Analysis}

In this study we have focused exclusively on how resources are managed for innovation; thus, synchronization of the resource orchestration processes is theorized to be a relevant moderator in this relationship. While we did not develop theory for, or hypothesize direct effects of synchronization, we can examine this empirically. ${ }^{\mathrm{v}}$ Prior research in $\mathrm{RO}$ has focused on the benefits of synchronization (Sirmon and Hitt, 2009, Sirmon, et al., 2011). But there is additional research in innovation that suggests that this direct effect may be curvilinear. Specifically, Kahn (1996) and Kahn and Mentzer (1998) found that very high levels of interdepartmental integration may create inefficiency or inefficacy, especially in innovation processes. Other research has found that a significant emphasis on improving the efficiency and coordination of internal activities has the potential to create rigidity as opposed to the adaptability needed for innovation 
(Leonard-Barton, 1992). As seen in Table 3, Models 2-5, synchronization has a significant positive direct effect on innovation. This result is robust in both the low- and high-performance subgroups as well. When the squared term of synchronization is included in the model as well, the coefficient of the direct effect remains positive and significant $(p<0.001)$ and the coefficient of the squared term is negative and significant $(\mathrm{p}<0.001)$, indicating an inverted U-shaped relationship. ${ }^{\text {vi }}$ These results are substantially similar in both the high-performance subgroup $(\mathrm{p}<0.001)$ and low-performance subgroup $(\mathrm{p}<0.01)$. This supports the notion that while synchronization is beneficial for innovation, 'too much of a good thing' can eventually outweigh the benefits.

\section{DISCUSSION}

In 1959, Penrose suggested that managing resources is at least as important as owning them; however, it was not until recently that research has focused on the internal portion of the "black box" to understand how resources must be managed to create value (Lin, et al., 2017, Priem and Butler, 2001, Sirmon, et al., 2007). The present study integrates RO with BTOF to investigate the joint effect of synchronization and leveraging strategies on innovation under different relative performance contexts. Our results suggest that RO processes influence firm innovation and that synchronization in particular is, indeed, critical to the effectiveness of the RO processes, beyond the main effects of the structuring and bundling processes and leveraging strategies alone. These findings support arguments from previous theoretical work on RO (Sirmon, et al., 2011) and identify a substantial interrelationship between internal actions (synchronization) and external market engagement choices (leveraging strategies).

Building on the BTOF, we also examined how a firm's performance relative to rivals moderates the interaction between leveraging strategy and synchronization as they relate to 
innovation. Specifically, this synergistic relationship is contextually dependent on the firm's performance due to the importance of fit between a firm's leveraging strategy and its performance aspirations (i.e., to maintain a current position or to improve its performance relative to other firms). In our findings, synchronization strengthens the influence of both the resource advantage and market opportunity strategies on innovation for high performance firms but does not influence the entrepreneurial strategy's effect on innovation. Alternatively, for low performance firms, additional benefits from synchronization were only observed when the entrepreneurial strategy was employed but not for the resource advantage or market opportunity strategy.

\subsection{Implications}

Several important theoretical contributions emerge from this work. First, we extend the focus of the empirical research on RO to include innovation, which is important to the competitive position of firms in many industries. While innovation has been widely studied as a firm-level outcome, it has not been specifically linked to RO activities theoretically or empirically in previous research. The effects of RO have traditionally focused on firm performance (Sirmon, et al., 2007); herein we answer previous calls (Lin, et al., 2017) to address a lack of research on RO and innovation. Our findings are the first to provide empirical support for the contention that synchronization of the firm's resources, capabilities, and strategies plays a critical role in the development of innovation (Sirmon, et al., 2011). Paladino (2007) showed that holding valuable resources is important for firms to be innovative. Our contextually rich approach extends this understanding by demonstrating that it is not only resources, but resource orchestration processes, such as synchronization, that influence innovation outcomes. 
Second, our study unites RO with BTOF to produce deeper insights, highlighting the importance of fit between a firm and its market strategies to achieve innovation outcomes (De Massis, et al., 2018, Troilo, et al., 2014). We offer a contingency perspective on the relationship among synchronization, leveraging strategies, and innovation. Our finding that the positive synergistic benefits of synchronization are present when a firm's leveraging strategy is aligned with its aspirations as determined by the firm's relative performance clarifies the mixed results from previous empirical studies (Huesch, 2013, Sirmon and Hitt, 2009).

Relatedly, our work also extends previous studies that have focused on the contingent role of strategic actions in the resources-innovation relationship. For example, Troilo et al. (2014) theorize and show that the effect of slack resources on radical innovation are contingent on Miles and Snow's (1978) typology of strategies, which is based on the firm's orientation toward innovation and on the scope of the environmental scanning it implements to seek information (prospectors aim to be the first to introduce highly innovative new products; defenders seldom engage in innovation; analysers blend the characteristics of prospectors and defenders) (Sirmon, et al., 2007). By integrating the theoretical bases of RO and BTOF, our work offers a more focused and compelling understanding of how synchronization and leveraging strategies jointly affect innovation as a function of the firm's performance level, and specifically indicates what combination of these variables produces the strongest innovation potential. In addition to the theoretical contributions, this study also has implications for managers. Synchronization of internal activities, processes, and subunits involves significant managerial attention, time, and other resources to implement effectively (Joglekar and Rosenthal, 2003, Sirmon and Hitt, 2009). For executives, the takeaway is that a proper fit between the firm's relative performance and the leveraging strategy chosen is needed to ensure that an investment in 
synchronization will yield additional, synergistic gains in innovativeness. And, in line with prior work (Kahn, 1996, Kahn and Mentzer, 1998), our post-hoc analysis showing the inverted Ushaped relationship between synchronization and innovation indicates to managers that internal checks are necessary to ensure synchronization is not taken to an extreme such that inefficiencies and costs outweigh the potential positive direct and synergistic benefits of synchronization. Thus, this research offers practitioners an understanding of the organizational processes that support innovation, beyond just R\&D.

\subsection{Limitations and Future Research}

This work is not without limitations, which suggest rich areas for future research. The first limitation relates to the general nature of the dependent variable, innovation, used in this study. Our measure did not track differences in types of innovation (e.g., incremental vs. novel innovation) produced by each configuration of $\mathrm{RO}$ activities and strategies; this presents an opportunity for a more fine-grained future analysis. Further, although we controlled for $R \& D$ intensity, we did not include objective measures of innovative output such as a count of patents or new products. The use of the policy capturing technique measures innovation based on a manager's judgment of innovative propensity. Use of objective measures in a future study could further extend our understanding. A second limitation concerns slack, which we treat conceptually but not empirically in this study. Here, we theorize slack's role in the ROinnovation relationship, and we refer to excess resources in terms of slack, but we don't directly measure level or type of slack resources. Future studies should incorporate fine-grained measures of the types of slack and their potential effects on specific types of innovation (Gibbert, et al., 2014, Troilo, et al., 2014). 
Finally, future studies present an opportunity to collect secondary data on firm historical performance aspirations for incorporation into our model. Building on both the RO and BTOF theoretical frameworks, this study made a key contribution in measuring how a firm's perceived context (i.e., firm's performance compared to those of competitors) influences managers' decision-making processes, and ultimately the value of synchronization. Our framing was supported by our findings from the validation interviews, in which seven of the eight respondents indicated that performance relative to rivals is of major importance in their assessment and decision-making processes. The consensus was that relative performance creates the most pressure for managers and is on the 'top of their mind' in their strategic decision making. Given that "[a]11 aspirations are not created equal" (Kim, Finkelstein and Haleblian, 2015: 1361), future work could yield new insights by further delineation of relative performance and aspirations, beyond the binary categorization of high and low relative performance used in this study.

Additionally, it could be valuable to explore how different contexts and contingencies may influence synchronization, leveraging strategy, and innovation. Does public versus private or family ownership differentiate managerial decision frameworks, for example with shorter or longer-term orientations, in ways that influence synchronization and innovation? Could a firm's life cycle stage influence the importance of different RO activities within that firm and thus change the importance of synchronization for achieving superior returns? Further, our study did not address environmental conditions apart from controlling for general industry influences. How might specific environmental attributes such as industry dynamism or munificence influence firm activities? For example, firms competing in a dynamic, fast-cycle market may have to take risks and act boldly in product development in order to maintain their current competitive position (e.g. Derfus et al., 2008). In such conditions, how might firm risk preferences change? 
And do these changing preferences introduce important considerations in decisions regarding synchronization, strategies, and innovation? Also, while we limited our scope to the use of leveraging strategies in individual markets, it could be of value to explore a portfolio of strategies in which two or more different strategies are used in separate product or geographic markets simultaneously. What sort of risk (or balancing thereof) might be introduced when firms pursue multiple strategies? Could managers synchronize activities across all strategies to achieve integration operating in different markets? Are there benefits to synchronizing $\mathrm{RO}$ activities across firm strategies, or would the difficulties of doing so outweigh the benefits? Future research could examine these research questions.

In sum, this study provides a foundational understanding of how RO processes, specifically synchronization and leveraging strategies, have differential effects on innovation, moderated by the firm's relative performance. It sharpens our understanding of how firms can most strategically use synchronization to enhance innovation depending on the firm's context and indicates promising avenues for future research that will further broaden our theoretical understanding of the processes that support innovation. 


\section{REFERENCES:}

Agarwal, R., Sarkar, M. and Echambadi, R. (2002). The conditioning effect of time on firm survival: An industry life cycle approach. Academy of Management Journal 45(5), 971-994.

Ahuja, G., Lampert, C.M. and Tandon, V. (2008). Moving Beyond Schumpeter: Management Research on the Determinants of Technological Innovation. Academy of Management Annals 2(1), 1-98.

Alexy, O., Bascavusoglu-Moreau, E. and Salter, A.J. (2016). Toward an aspiration-level theory of open innovation. Industrial and Corporate Change 25(2), 289-306.

Antioco, M., Moenaert, R.K. and Lindgreen, A. (2008). Reducing Ongoing Product Design DecisionMaking Bias. Journal of Product Innovation Management 25(6), 528-545.

Arnold, H.J. (1982). Moderator variables: A clarification of conceptual, analytic, and psychometric issues. Organizational Behavior and Human Performance 29(2), 143-174.

Arrfelt, M., Wiseman, R.M. and Hult, G.T.M. (2013). Looking backward instead of forward: Aspirationdriven influences on the efficiency of the capital allocation process. Academy of Management Journal 56(4), 1081-1103.

Baert, C., Meuleman, M., Debruyne, M. and Wright, M. (2016). Portfolio Entrepreneurship and Resource Orchestration. Strategic Entrepreneurship Journal 10(4), 346-370.

Baker, T. and Nelson, R.E. (2005). Creating Something from Nothing: Resource Construction through Entrepreneurial Bricolage. Administrative Science Quarterly 50(3), 329-366.

Bardolet, D., Fox, C.R. and Lovallo, D. (2011). Corporate capital allocation: a behavioral perspective. Strategic Management Journal 32(13), 1465-1483.

Barney, J. (1991). Firm resources and sustained competitive advantage. Journal of Management 17(1), 99-120.

Barreto, I. (2012). A Behavioral Theory of Market Expansion Based on the Opportunity Prospects Rule. Organization Science 23(4), 1008-1023.

Bollinger, M., Josefy, M., Stevenson, R. and Hitt, M.A. (2021). Experiments in Strategy Research: A Critical Review and Future Research Opportunities. Journal of Management.

Bonaccorsi, A. and Lipparini, A. (1994). Strategic partnerships in new product development: An Italian case study. Journal of Product Innovation Management 11(2), 134-145.

Branzei, O. and Vertinsky, I. (2006). Strategic pathways to product innovation capabilities in SMEs. Journal of Business Venturing 21(1), 75-105.

Chandy, R.K. and Tellis, G.J. (2000). The Incumbent's Curse? Incumbency, Size, and Radical Product Innovation. Journal of Marketing 64(3), 1-17.

Chen, W.-R. (2008). Determinants of firms' backward-and forward-looking R\&D search behavior. Organization Science 19(4), 609-622.

Chen, W.-R. and Miller, K.D. (2007). Situational and institutional determinants of firms' R\&D search intensity. Strategic Management Journal 28(4), 369-381.

Coates, T.T. and McDermott, C.M. (2002). An exploratory analysis of new competencies: a resource based view perspective. Journal of Operations Management 20(5), 435-450.

Cohen, W.M. and Levinthal, D.A. (1990). Absorptive Capacity: A New Perspective on Learning and Innovation. Administrative Science Quarterly 35(1), 128-152.

Connelly, B.L., Miller, T. and Devers, C.E. (2012). Under a cloud of suspicion: trust, distrust, and their interactive effect in interorganizational contracting. Strategic Management Journal 33(7), 820-833.

Cyert, R.M. and March, J.G. (1963). A behavioral theory of the firm. Englewood Cliffs, NJ: PrenticeHall.

Cyert, R.M. and March, J.G. (1992). A behavioral theory of the firm (2nd ed.). Cambridge, MA: Blackwell.

Danneels, E. (2002). The dynamics of product innovation and firm competences. Strategic Management Journal 23(12), 1095-1121. 
De Massis, A., Audretsch, D., Uhlaner, L. and Kammerlander, N. (2018). Innovation with Limited Resources: Management Lessons from the German Mittelstand. Journal of Product Innovation Management 35(1), 125-146.

Derfus, P.J., Maggitti, P.G., Grimm, C.M. and Smith, K.G. (2008). The red queen effect: competitive actions and firm performance. Academy of Management Journal 51(1), 61-80.

Devers, C.E., Wiseman, R.M. and Holmes, R.M. (2007). The effects of endowment and loss aversion in managerial stock option valuation. Academy of Management Journal 50(1), 191-208.

Emden, Z., Calantone, R.J. and Droge, C. (2006). Collaborating for New Product Development: Selecting the Partner with Maximum Potential to Create Value. Journal of Product Innovation Management 23(4), 330-341.

Evanschitzky, H., Eisend, M., Calantone, R.J. and Jiang, Y. (2012). Success Factors of Product Innovation: An Updated Meta-Analysis. Journal of Product Innovation Management 29, 21-37.

Fleming, L. (2001). Recombinant Uncertainty in Technological Search. Management Science 47(1), 117132.

Gaba, V. and Bhattacharya, S. (2012). Aspirations, innovation, and corporate venture capital: A behavioral perspective. Strategic Entrepreneurship Journal 6(2), 178-199.

George, G. (2005). Slack resources and the performance of privately held firms. Academy of Management Journal 48(4), 661-676.

Gibbert, M., Hoegl, M. and Valikangas, L. (2014). Introduction to the Special Issue: Financial Resource Constraints and Innovation. Journal of Product Innovation Management 31(2), 197-201.

Gómez-Mejía, L.R., Haynes, K.T., Núñez-Nickel, M., Jacobson, K.J. and Moyano-Fuentes, J. (2007). Socioemotional wealth and business risks in family-controlled firms: evidence from Spanish olive oil mills. Administrative Science Quarterly 52(1), 106-137.

Greer, C., Lusch, R. and Hitt, M. (2017). A Service Perspective for Human Capital Resources: A Critical Base for Strategy Implementation. Academy of Management Perspectives, amp.2016.0004.

Greve, H.R. (2003). A Behavioral Theory of R\&D Expenditures and Innovations: Evidence from Shipbuilding. Academy of Management Journal 46(6), 685-702.

Harris, J. and Bromiley, P. (2007). Incentives to Cheat: The Influence of Executive Compensation and Firm Performance on Financial Misrepresentation. Organization Science 18(3), 350-367.

Helfat, C.E. and Peteraf, M.A. (2003). The dynamic resource-based view: capability lifecycles. Strategic Management Journal 24(10), 997-1010.

Hitt, M., Nixon, R., Hoskisson, R. and Kochhar, R. (1999). Corporate Entrepreneurship and CrossFunctional Fertilization: Activation, Process and Disintegration of a New Product Design Team. Entrepreneurship Theory and Practice 23(3), 145-167.

Hitt, M.A., Ahlstrom, D., Dacin, M.T., Levitas, E. and Svobodina, L. (2004a). The institutional effects on strategic alliance partner selection in transition economies: China vs. Russia. Organization Science 15(2), 173-185.

Hitt, M.A., Boyd, B.K. and Li, D. (2004b). The State of Strategic Management Research and a Vision of the Future. In: Research Methodology in Strategy and Management, pp. 1-31.

Hitt, M.A., Dacin, M.T., Levitas, E., Arregle, J.-L. and Borza, A. (2000). Partner selection in emerging and developed market contexts: Resource-based and organizational learning perspectives. Academy of Management Journal 43(3), 449-467.

Hitt, M.A., Jackson, S.E., Carmona, S., Bierman, L., Shalley, C.E. and Wright, D.M. (2017). The Future of Strategy Implementation. In: The Oxford Handbook of Strategy Implementation. Michael A. Hitt, Susan E. Jackson, Salvador Carmona, Leonard Bierman, Christina E. Shalley and Douglas Michael Wright (eds.).

Hitt, M.A. and Middlemist, R.D. (1979). A methodology to develop the criteria and criteria weightings for assessing subunit effectiveness in organizations. Academy of Management Journal 22(2), 356374.

Hofmann, D.A. (1997). An overview of the logic and rationale of hierarchical linear models. Journal of Management 23(6), 723-744. 
Hoskisson, R.E., Chirico, F., Zyung, J. and Gambeta, E. (2017). Managerial Risk Taking. Journal of Management 43(1), 137-169.

Hrebiniak, L. (2005). Business strategy: execution is the key. Financial Times.

Huesch, M.D. (2013). Are there always synergies between productive resources and resource deployment capabilities? Strategic Management Journal 34(11), 1288-1313.

Joglekar, N.R. and Rosenthal, S.R. (2003). Coordination of Design Supply Chains for Bundling Physical and Software Products. Journal of Product Innovation Management 20(5), 374-390.

Kahn, K. (1996). Interdepartmental integration: A definition with implications for product development performance. Journal of Product Innovation Management 13(2), 137-151.

Kahn, K.B. and Mentzer, J.T. (1998). Marketing's Integration with Other Departments. Journal of Business Research 42(1), 53-62.

Kim, J.-Y., Finkelstein, S. and Haleblian, J. (2015). All aspirations are not created equal: The differential effects of historical and social aspirations on acquisition behavior. Academy of Management Journal 58(5), 1361-1388.

Kleinschmidt, E.J., De Brentani, U. and Salomo, S. (2007). Performance of Global New Product Development Programs: A Resource-Based View. Journal of Product Innovation Management 24(5), 419-441.

Kotlar, J., Fang, H., De Massis, A. and Frattini, F. (2014). Profitability Goals, Control Goals, and the R\&D Investment Decisions of Family and Nonfamily Firms. Journal of Product Innovation Management 31(6), 1128-1145.

Kusunoki, K. (1997). Incapability of technological capability: A case study on product innovation in the Japanese facsimile machine industry. Journal of Product Innovation Management 14(5), 368-382.

Latham, S.F. and Braun, M. (2009). Managerial Risk, Innovation, and Organizational Decline. Journal of Management 35(2), 258-281.

Leonard-Barton, D. (1992). Core capabilities and core rigidities: A paradox in managing new product development. Strategic Management Journal 13(S1), 111-125.

Lichtenstein, B.M.B. and Brush, C.G. (2001). How do "resource bundles" develop and change in new ventures? A dynamic model and longitudinal exploration. Entrepreneurship: Theory and Practice 25(3), 37-37.

Lin, H.-E., McDonough, E.F., Yang, J. and Wang, C. (2017). Aligning Knowledge Assets for Exploitation, Exploration, and Ambidexterity: A Study of Companies in High-Tech Parks in China. Journal of Product Innovation Management 34(2), 122-140.

Makri, M., Hitt, M.A. and Lane, P.J. (2010). Complementary technologies, knowledge relatedness, and invention outcomes in high technology mergers and acquisitions. Strategic Management Journal $31(6), 602-628$.

Massini, S., Lewin, A.Y. and Greve, H.R. (2005). Innovators and imitators: Organizational reference groups and adoption of organizational routines. Research Policy 34(10), 1550-1569.

Miles, R.E. and Snow, C.C. (1978). Organizational Strategy, Structure and Process. New York: McGraw-Hill Book Company.

Miller, D., Eisenstat, R. and Foote, N. (2002). Strategy from the Inside Out: Building Capability-Creating Organizations. California Management Review 44(3), 37-54.

Mishina, Y., Dykes, B.J., Block, E.S. and Pollock, T.G. (2010). Why "good" firms do bad things: The efects of high aspirations, high expectations, and prominence on the incidence of corproate illegality. Academy of Management Journal 53(4), 701-722.

Morrow, J.L., Sirmon, D.G., Hitt, M.A. and Holcomb, T.R. (2007). Creating value in the face of declining performance: firm strategies and organizational recovery. Strategic Management Journal 28(3), 271283.

Nelson, R.R. and Winter, S.G. (1982). The Schumpeterian tradeoff revisited. The American Economic Review 72(1), 114-132.

O'Brien, J. and David, P. (2014). Reciprocity and R\&D search: Applying the behavioral theory of the firm to a communitarian context. Strategic Management Journal 35, 550-565. 
Paladino, A. (2007). Investigating the Drivers of Innovation and New Product Success: A Comparison of Strategic Orientations. Journal of Product Innovation Management 24(6), 534-553.

Pollok, P., Lüttgens, D. and Piller, F.T. (2019). How Firms Develop Capabilities for Crowdsourcing to Increase Open Innovation Performance: The Interplay between Organizational Roles and Knowledge Processes. Journal of Product Innovation Management 36(4), 412-441.

Priem, R.L. and Butler, J.E. (2001). Is the Resource-Based "View" a Useful Perspective for Strategic Management Research? Academy of Management Review 26(1), 22-40.

Randhawa, K., Wilden, R. and Gudergan, S. (2018). Open Service Innovation: The Role of Intermediary Capabilities. Journal of Product Innovation Management 35(5), 808-838.

Repenning, N.P. (2002). A Simulation-Based Approach to Understanding the Dynamics of Innovation Implementation. Organization Science 13(2), 109-127.

Reuer, J.J., Tong, T.W., Tyler, B.B. and Ariño, A. (2013). Executive preferences for governance modes and exchange partners: An information economics perspective. Strategic Management Journal 34(9), 1104-1122.

Singh, J.V. (1986). Performance, slack, and risk taking in organizational decision making. Academy of Management Journal 29(3), 562-585.

Sirmon, D.G. and Hitt, M.A. (2003). Managing resources: Linking unique resources, management, and wealth creation in family firms. Entrepreneurship Theory and Practice 27(4), 339-358.

Sirmon, D.G. and Hitt, M.A. (2009). Contingencies within dynamic managerial capabilities: interdependent effects of resource investment and deployment on firm performance. Strategic Management Journal 30(13), 1375-1394.

Sirmon, D.G., Hitt, M.A. and Ireland, R.D. (2007). Managing firm resources in dynamic environments to create value: looking inside the black box. Academy of Management Review 32(1), 273-292.

Sirmon, D.G., Hitt, M.A., Ireland, R.D. and Gilbert, B.A. (2011). Resource orchestration to create competitive advantage: breadth, depth, and life cycle effects. Journal of Management 37(5), 13901412.

Song, L.Z., Song, M. and Anthony Di Benedetto, C. (2011). Resources, supplier investment, product launch advantages, and first product performance. Journal of Operations Management 29(1-2), 86104.

Starr, J.A. and MacMillan, I.C. (1990). Resource cooptation via social contracting: Resource acquisition strategies for new ventures. Strategic Management Journal 11(4), 79-92.

Stumpf, S.A. and London, M. (1981). Capturing Rater Policies in Evaluating Candidates for Promotion. Academy of Management Journal 24(4), 752-766.

Subramaniam, M. and Venkatraman, N. (2001). Determinants of transnational new product development capability: testing the influence of transferring and deploying tacit overseas knowledge. Strategic Management Journal 22(4), 359-378.

Tong, T.W., Reuer, J.J., Tyler, B.B. and Zhang, S. (2015). Host country executives' assessments of international joint ventures and divestitures: An experimental approach. Strategic Management Journal 36(2), 254-275.

Troilo, G., De Luca, L.M. and Atuahene-Gima, K. (2014). More Innovation with Less? A Strategic Contingency View of Slack Resources, Information Search, and Radical Innovation. Journal of Product Innovation Management 31(2), 259-277.

Venkatraman, N. (1989). The concept of fit in strategy research: Toward verbal and statistical correspondence. Academy of Management Review 14(3), 423-444.

Vissa, B., Greve, H.R. and Chen, W.-R. (2010). Business group affiliation and firm search behavior in India: responsiveness and focus of attention. Organization Science 21(3), 696-712.

Voss, G.B., Sirdeshmukh, D. and Voss, Z.G. (2008). The effects of slack resources and environmentalthreat on product exploration and exploitation. Academy of Management Journal 51(1), 147-164.

Wernerfelt, B. (1984). A resource-based view of the firm. Strategic Management Journal 5(2), 171-180. 
Wiklund, J. and Shepherd, D. (2003). Knowledge-based resources, entrepreneurial orientation, and the performance of small and medium-sized businesses. Strategic Management Journal 24(13), 13071314.

Zahra, S.A. and Nielsen, A.P. (2002). Sources of capabilities, integration and technology commercialization. Strategic Management Journal 23(5), 377-398. 
Table 1

Independent and Dependent Variable Descriptive Statistics and Correlations

\begin{tabular}{|c|c|c|c|c|c|c|c|c|c|c|c|c|c|c|}
\hline & & Mean & $\begin{array}{c}\text { St. } \\
\text { Dev. }\end{array}$ & 1 & 2 & 3 & 4 & 5 & 6 & 7 & 8 & 9 & 10 & 11 \\
\hline 1 & Acquiring & 3.27 & 1.39 & 1.00 & & & & & & & & & & \\
\hline 2 & Accumulating & 2.87 & 1.41 & -0.10 & 1.00 & & & & & & & & & \\
\hline 3 & Divesting & 2.50 & 1.34 & -0.04 & 0.12 & 1.00 & & & & & & & & \\
\hline 4 & Stabilizing & 3.17 & 1.34 & 0.12 & -0.32 & 0.23 & 1.00 & & & & & & & \\
\hline 5 & Enriching & 3.10 & 1.47 & -0.09 & 0.05 & 0.13 & 0.23 & 1.00 & & & & & & \\
\hline 6 & Pioneering & 2.73 & 1.34 & 0.24 & -0.05 & -0.02 & 0.19 & -0.04 & 1.00 & & & & & \\
\hline 7 & Resource Advantage Strategy & 2.77 & 1.45 & 0.10 & -0.28 & -0.21 & 0.00 & -0.21 & -0.03 & 1.00 & & & & \\
\hline 8 & Market Opportunity Strategy & 3.00 & 1.48 & -0.21 & -0.27 & -0.25 & -0.28 & 0.18 & -0.25 & 0.15 & 1.00 & & & \\
\hline 9 & Entrepreneurial Strategy & 2.77 & 1.41 & -0.04 & -0.15 & -0.15 & -0.01 & -0.26 & -0.02 & 0.01 & 0.24 & 1.00 & & \\
\hline 10 & Synchronization & 2.87 & 1.41 & 0.00 & 0.26 & 0.20 & 0.12 & -0.04 & -0.11 & -0.23 & -0.21 & -0.10 & 1.00 & \\
\hline 11 & Performance & 3.70 & 0.74 & 0.00 & 0.00 & 0.00 & 0.00 & 0.00 & 0.00 & 0.00 & 0.00 & 0.00 & 0.00 & 1.00 \\
\hline 12 & Innovation & 2.56 & 0.93 & 0.12 & 0.09 & -0.02 & 0.00 & 0.05 & 0.06 & 0.07 & 0.14 & 0.19 & 0.12 & -0.02 \\
\hline
\end{tabular}

Table 2

Control Variables Descriptive Statistics and Correlations 


\begin{tabular}{|c|c|c|c|c|c|c|c|c|c|c|c|}
\hline & & Mean & $\begin{array}{c}\text { St. } \\
\text { Dev }\end{array}$ & 1 & 2 & 3 & 4 & 5 & 6 & 7 & 8 \\
\hline 1 & R\&D Intensity & 22.00 & 21.23 & 1.00 & & & & & & & \\
\hline 2 & Size & 4.42 & 3.17 & -0.13 & 1.00 & & & & & & \\
\hline 3 & Family Business & 0.31 & 0.46 & -0.12 & -0.30 & 1.00 & & & & & \\
\hline 4 & Life Cycle Stage & 2.65 & 1.02 & -0.37 & 0.41 & 0.02 & 1.00 & & & & \\
\hline 5 & Industry 1 (Mineral \& Construction) & 0.13 & 0.34 & -0.14 & -0.06 & 0.22 & -0.11 & 1.00 & & & \\
\hline 6 & Industry 2 (Manufacturing) & 0.11 & 0.31 & 0.01 & 0.15 & 0.12 & 0.15 & -0.14 & 1.00 & & \\
\hline 7 & Industry 3 (Services) & 0.59 & 0.49 & -0.13 & 0.05 & -0.11 & 0.01 & -0.47 & -0.42 & 1.00 & \\
\hline 8 & Industry 4 (Public Admin \& Other) & 0.10 & 0.30 & 0.45 & -0.09 & -0.22 & -0.10 & -0.13 & -0.12 & -0.40 & 1.00 \\
\hline 9 & Industry 5 (Wholesale, Retail, Transportation) & 0.07 & 0.25 & -0.10 & -0.09 & 0.04 & 0.06 & -0.10 & -0.09 & -0.32 & -0.09 \\
\hline
\end{tabular}


Table 3

HLM Results ${ }^{\mathrm{a}}$

\begin{tabular}{|c|c|c|c|c|c|c|c|c|c|c|c|c|c|c|c|}
\hline \multirow[b]{2}{*}{ Controls } & \multicolumn{3}{|c|}{ Model 1} & \multicolumn{3}{|c|}{ Model 2} & \multicolumn{3}{|c|}{ Model 3} & \multicolumn{3}{|c|}{$\begin{array}{l}\text { Model 4: High Perf. } \\
\text { Subgroup }\end{array}$} & \multicolumn{3}{|c|}{$\begin{array}{l}\text { Model 5: Low Perf. } \\
\text { Subgroup }\end{array}$} \\
\hline & Coeff. & & S.E. & Coeff. & & S.E & Coeff. & & S.E. & Coeff. & & S.E. & Coeff. & & S.E. \\
\hline Intercept & 2.59 & $* *$ & 0.17 & 2.59 & $* *$ & 0.17 & 2.61 & $* *$ & 0.17 & 2.28 & $* *$ & 0.27 & 3.02 & $* *$ & 0.20 \\
\hline R\&D intensity & 0.00 & & 0.00 & 0.00 & & 0.00 & 0.00 & & 0.00 & 0.00 & & 0.00 & 0.00 & + & 0.00 \\
\hline Size & 0.02 & & 0.01 & 0.02 & & 0.01 & 0.02 & & 0.01 & 0.01 & & 0.02 & 0.03 & $*$ & 0.01 \\
\hline Family business & -0.05 & & 0.08 & -0.05 & & 0.08 & -0.05 & & 0.08 & -0.02 & & 0.13 & 0.02 & & 0.09 \\
\hline Life cycle stage & -0.03 & & 0.04 & -0.03 & & 0.04 & -0.03 & & 0.04 & 0.03 & & 0.06 & -0.10 & $* *$ & 0.04 \\
\hline Industry 1 (Mineral \& Construction) & 0.11 & & 0.15 & 0.11 & & 0.15 & 0.11 & & 0.15 & 0.26 & & 0.23 & -0.16 & & 0.18 \\
\hline Industry 2 (Manufacturing) & -0.08 & & 0.16 & -0.08 & & 0.16 & -0.08 & & 0.16 & 0.05 & & 0.22 & -0.25 & & 0.20 \\
\hline $\begin{array}{l}\text { Industry } 3 \text { (Financial, Services, } \\
\text { Communications) }\end{array}$ & 0.03 & & 0.13 & 0.03 & & 0.13 & 0.03 & & 0.13 & 0.23 & & 0.20 & -0.25 & & 0.16 \\
\hline Industry 4 (Public Admin \& Other) & 0.10 & & 0.17 & 0.10 & & 0.17 & 0.10 & & 0.17 & 0.32 & & 0.28 & -0.11 & & 0.19 \\
\hline Acquiring & 0.09 & $* *$ & 0.01 & 0.11 & $* *$ & 0.01 & 0.12 & $* *$ & 0.01 & 0.13 & $* *$ & 0.01 & 0.10 & $* *$ & 0.02 \\
\hline Accumulating & 0.07 & $* *$ & 0.01 & 0.13 & $* *$ & 0.01 & 0.16 & $* *$ & 0.01 & 0.17 & $* *$ & 0.02 & 0.13 & $* *$ & 0.02 \\
\hline Divesting & -0.03 & $*$ & 0.01 & 0.02 & & 0.01 & 0.01 & & 0.01 & 0.01 & & 0.02 & 0.02 & & 0.02 \\
\hline Stabilizing & 0.01 & & 0.01 & 0.03 & $*$ & 0.01 & 0.05 & $* *$ & 0.01 & 0.07 & $* *$ & 0.02 & 0.04 & & 0.02 \\
\hline Enriching & 0.04 & $* *$ & 0.01 & 0.07 & $* *$ & 0.01 & 0.05 & $* *$ & 0.01 & 0.05 & $* *$ & 0.02 & 0.05 & $* *$ & 0.02 \\
\hline Pioneering & 0.02 & $*$ & 0.01 & 0.07 & $* *$ & 0.01 & 0.09 & $* *$ & 0.01 & 0.09 & $* *$ & 0.02 & 0.08 & $* *$ & 0.02 \\
\hline $\begin{array}{l}\text { Leveraging Strategies and } \\
\text { Synchronization }\end{array}$ & & & & & & & & & & & & & & & \\
\hline Synchronization & & & & 0.12 & $* *$ & 0.01 & 0.11 & $* *$ & 0.01 & 0.13 & $* *$ & 0.01 & 0.09 & $* *$ & 0.02 \\
\hline Resource advantage strategy & & & & 0.09 & $* *$ & 0.01 & 0.09 & $* *$ & 0.01 & 0.09 & $* *$ & 0.01 & 0.10 & $* *$ & 0.02 \\
\hline Market opportunity strategy & & & & 0.13 & $* *$ & 0.01 & 0.14 & $* *$ & 0.01 & 0.14 & $* *$ & 0.02 & 0.14 & $* *$ & 0.02 \\
\hline Entrepreneurial strategy & & & & 0.15 & $* *$ & 0.01 & 0.14 & $* *$ & 0.01 & 0.13 & $* *$ & 0.01 & 0.16 & $* *$ & 0.02 \\
\hline Interaction Effects & & & & & & & & & & & & & & & \\
\hline $\begin{array}{l}\text { Synchronization x Resource advantage } \\
\text { strategy }\end{array}$ & & & & & & & 0.01 & $*$ & 0.01 & 0.02 & $*$ & 0.01 & 0.00 & & 0.01 \\
\hline $\begin{array}{l}\text { Synchronization x Market opportunity } \\
\text { strategy }\end{array}$ & & & & & & & 0.02 & $*$ & 0.01 & 0.03 & $* *$ & 0.01 & 0.00 & & 0.01 \\
\hline Synchronization x Entrepreneurial strategy & & & & & & & 0.01 & + & 0.01 & 0.01 & & 0.01 & 0.02 & * & 0.01 \\
\hline Number of Observations & 3600 & & & 3600 & & & 3600 & & & 2070 & & & 1530 & & \\
\hline Number of Groups & 120 & & & 120 & & & 120 & & & 69 & & & 51 & & \\
\hline Wald Chi-Squared Test & 136.31 & $* *$ & & 756.64 & $* *$ & & 775.18 & $* *$ & & 489.39 & $* *$ & & 323.88 & $* *$ & \\
\hline
\end{tabular}

${ }^{a}$ One tailed tests for predictors, two-tailed tests for controls; $+\mathrm{p}<.10,{ }^{*} \mathrm{p}<.05, * * \mathrm{p}<.01, * * * \mathrm{p}<.001$ 


\section{ENDNOTES}

${ }^{\mathrm{i}}$ This example arose from one of our respondents during our validation interviews (detailed in the methods section). Specifically, this respondent was a senior manager with a large media distribution company ( $\sim 1$ billion in revenues and 3,000 employees).

ii We did not vary the order of the scenarios presented; however, comparison tests revealed that results are substantially similar if we exclude the last five scenarios, both the first and the last five scenarios (i.e., only looking at the middle 20), and even if we only consider the odd numbered scenarios as a way to take a 'random' sample of all of our scenarios.

iii A three-cluster solution, as well as a simple median split was used in additional analyses and all provided similar results as those based on the two-cluster solution.

iv Life cycle was also operationalized as 4 dummy variables in additional analyses yielding substantially similar results.

${ }^{\mathrm{v}}$ We thank one of our reviewers for highlighting this important point.

${ }^{v i}$ Results of this post-hoc analysis are available on request. 